\title{
Diseño de la base de datos de sermones impresos durante el siglo XvII en la Nueva España ${ }^{1}$
}

\section{Design of the Database of Sermons Printed in $17^{\text {th }}$ Century New Spain}

\author{
Cecilia A. Cortés Ortiz \\ Universidad Nacional Autónoma de México \\ Instituto de Investigaciones Bibliográficas \\ cecilia.cortes@comunidad.unam.mx
}

\section{ResUMEN}

En este artículo se describe detalladamente la organización y el diseño de la base de datos de sermones impresos durante el siglo XVII en la Nueva España. Está compuesta por un total de trece tablas, conformadas a su vez por diversos campos, en los cuales se concentra de manera organizada y estructurada gran cantidad de información (autores, talleres de impresión, años de publicación, ciudades en las que se imprimieron, obras principales dentro de las que algunos sermones se encuentran contenidos, autores de los preliminares, mecenas de las obras, etcétera) relativa a todos los sermones impresos durante este siglo que fueron encontrados en los principales acervos que cuentan con Fondo Antiguo. Los datos almacenados pueden ser un punto de partida para futuras investigaciones que giren en torno al tema de la oratoria sagrada en la Nueva España.

\section{Palabras clave}

Sermones impresos, base de datos, predicación, siglo XVII, Nueva España.

\section{ABSTRACT}

The organization and design of the database of sermons printed during the $17^{\text {th }}$ century in New Spain is described in detail in this article. The database has thirteen tables with various fields that contain a great deal of information (authors, printing workshops, publication year, publication city, works that contain those sermons, other works by the same author, sponsors who financed the publication of the sermons, etcetera) regarding all of the sermons printed in that century that were

${ }^{1}$ Este proyecto de investigación se llevó a cabo en el Centro de Poética del Instituto de Investigaciones Filológicas, gracias al apoyo del Programa de Becas Posdoctorales de la UnAM. 
found in main collections with historical archives. This data can be a starting point for future research concerning the theme of sacred oratory in New Spain.

\section{KEYwORDS}

Sermons, database, preaching, $17^{\text {th }}$ century, New Spain.

RECEPCIÓN: 03/05/2018

ACEPTACIÓN: 03/09/2018*

\section{Introducción}

Se estima que, durante la Colonia, en México se imprimieron alrededor de dos mil piezas de oratoria sagrada (Herrejón: 19), lo cual evidencia que el sermón fue un género prolífico e importante en la época. Sin embargo, en la actualidad se encuentra poco valorado, quizá debido, en buena medida, a cierto prejuicio contemporáneo de nuestra sociedad secularizada, a la que le resulta especialmente dificil comprender el valor que tuvieron los sermones (tanto los impresos como los que sólo fueron pronunciados y no llegaron a las prensas) en la cultura y en la vida intelectual, literaria, social y política de los siglos XVI al XVIII. En dicho género, tan cotidiano y esencial para el México virreinal, confluyen diversos elementos interesantes que permiten estudiarlo desde distintos ángulos; por un lado, se encuentra el aspecto histórico, que proporciona información de acontecimientos importantes (como el nacimiento de un príncipe o la muerte de un rey o una reina) y de la vida cotidiana del momento (por ejemplo, las iglesias donde se predicaban sermones en diferentes festividades); por el otro, está el terreno narrativo, en el que se puede examinar, entre otras cosas, la gran cantidad de recursos retóricos y literarios (metáforas, similitudines o comparaciones, auctoritates o citas, elipsis, enumeraciones, metonimias, etcétera). Asimismo, dado que en los sermones convergen la oralidad y la escritura, es posible encontrar en ellos diferentes elementos de carácter oral, como refranes y exempla, pero también, gracias a las artes praedicandi, resulta factible conocer el complejo entramado retórico que implicaba el proceso de escritura de dichos textos.

En cuanto a su materialidad, cabe recordar que los sermones impresos novohispanos del siglo XVII son de una extensión aproximada de entre treinta y cincuenta páginas. La estructura que presentan, generalmente, se compone de la portada, los preliminares y el sermón. La primera contiene una gran fuente de información significativa para el análisis de un sermón, pues proporciona datos fundamentales de la obra: el título, quién lo predicó, en qué lugar y cuándo, la ciudad y el taller de impresión, y el año. En el caso de los segundos, pueden dividirse en: a) preliminares legales, es decir, los documentos

* Texto reservado para este número monográfico. 


\section{Diseño de la base de datos de sermones impresos}

necesarios para la publicación del sermón: tanto las licencias como las aprobaciones (también llamadas "censuras", "pareceres", "sentires"), a través de las cuales se dictaminaba el contenido del sermón para valorar si se apegaba a la doctrina católica y a las Sagradas Escrituras; y b) preliminares literarios, compuestos por la dedicatoria del autor o del mecenas que financió la publicación del sermón, algunos poemas, grabados de la Virgen o del santo al que se hace referencia, cartas al lector, entre otros (García: 218).

En lo relativo al sermón propiamente dicho, aunque en la práctica algunos de los elementos que lo debían conformar se modificaban u omitían según el gusto del predicador, en la teoría, los sermones temáticos constaban de las siguientes partes: el thema, cita bíblica en latín que, por lo general, se extraía de las lecturas de la liturgia del día (junto con ella debía enunciarse el libro del que provenía); el prothema, una segunda cita cuyo breve desarrollo conducía a la oratio, la cual no se empleó con mucha regularidad; la oratio o petición a la Virgen María como intercesora ante Dios, servía para encomendarle el sermón y pedirle que tuviera buenos frutos (también se llama salutación o salutatio); la thematis introductio, en la que se solía traducir el thema (la cita bíblica latina) a la lengua vulgar, así como mencionar el propósito del sermón, con una explicación breve de su contenido y del por qué de la pieza oratoria; la thematis divisio, parte en la que se dividía el thema en sus aspectos esenciales y determinaba la estructura del sermón, la división más frecuente era en tres partes, aunque un sermón podía tener más; la amplificatio, dilatatio o cuerpo del sermón estaba conformada por cada una de las partes de la divisio, las cuales se glosaban mediante recursos retóricos, tales como argumentaciones, etimologías, juegos de contrarios, metáforas, exempla, autoridades, distictiones, similitudines, vidas de santos, juegos de derivaciones por asociaciones, etcétera; la subdivisio, como su nombre lo indica, se componía de las subdivisiones o ramificaciones que tenía el desarrollo del sermón, las cuales debían comprobarse o autorizarse por medio de la Biblia; y, por último, la unitio o clausio, en la que se recogían los puntos principales del sermón para brindar una conclusión, por lo general, se empleaba una fórmula final que lo cerraba (Walde: 1-12).

Ahora bien, pese a su aludida importancia, en la actualidad no se cuenta con ningún trabajo que proporcione una visión panorámica de los sermones impresos durante el siglo XVII en la Nueva España. Realizar el rastreo, localización y registro de todos y cada uno de ellos resulta una tarea fundamental, debido a que, para estudiar cualquier materia, es necesario primero delimitarla, para después conocerla en profundidad y, posteriormente, elaborar análisis e interpretaciones. En ese sentido, como advertí, nunca antes se había emprendido un trabajo en el que se describiera con exactitud cuántas piezas de oratoria sagrada han sobrevivido al paso del tiempo, cuáles son y en dónde se encuentran resguardadas, ni tampoco se habían registrado los nombres de los predicadores que dieron a las prensas sus sermones, en qué lugar los pronunciaron, con qué motivo, en qué ciudades y qué impresores los entregaron a la estampa, entre 


\section{|Cecilia A. Cortés Ortiz}

otros datos. La investigación presentada a continuación pretende comenzar a subsanar el vacío existente en torno a la oratoria sagrada del siglo XVII, ya que el conocimiento y estudio de este género, un tanto olvidado, es esencial, a su vez, para trazar un panorama más completo de la historia de la literatura mexicana.

\section{¿Por qué es necesaria una base de datos?}

Para explicar los alcances y características de la base de datos de los sermones impresos novohispanos del siglo XVII presentados en este ensayo, resulta pertinente mencionar dos proyectos que llevé a cabo y que la anteceden. El primero es el "Catálogo de sermones impresos novohispanos del siglo XVII del Fondo Reservado de la Biblioteca Nacional", el cual documenta un total de 482 sermones que se encuentran resguardados en tres colecciones de dicho fondo: Lafragua, Cronológico Mexicano y el Fondo de Origen. Con la finalidad de mostrar cuáles son los datos registrados en este catálogo, a continuación se presenta una de las fichas catalográficas que lo conforman:

26 ARMENTIA, JOSÉ DE, O. P., Mystico verano. Sermon panegyrico
de la rosa predicado en su celebridad, que annual acostumbra hazer el Imperial
Convento de Predicadores, de esta Ciudad en concurrencia de la Invencion de la SS.
Cruz, y de la festiva solemnidad de la Seraphica Madre Santa Catharina de Sena,
que aplaude el Orden Tercero de Penitencia // Siempre fue costumbre de
los Antiguos, dedicar a la Diosa de las flores el presente mes de Mayo,
como que en el se ofreciesen un ameno, y delicioso Jardin de fragantí-
simas rosas, en el qual dilata la tierra, como fecunda madre, las tiernas
olorosas plantas..., México, Juan José Guillena Carrascoso, 1699, cla-
sificación: 1176 LAF.
(Grabado, dedicatoria, sentir, licencia, parecer, licencia, censura, licencia).
No. 116. ${ }^{2}$

Como puede apreciarse, la ficha contiene datos tomados de la portada (nombre del predicador, orden a la que pertenece, título del sermón, impresor, lugar de impresión y año), de los preliminares (el tipo de documentos que los conforman) y del sermón (su inicio). También, incluye la clasificación que le corresponde a la obra dentro de la Biblioteca Nacional de México; además, en caso de estar documentado en el repertorio Cartas pastorales, elogios fúnebres, oraciones, panegíricos, sermones y otros géneros de oratoria sagrada de la Colección Lafragua del Fondo Reservado de la Biblioteca Nacional de México, de Edelmira Ramírez Leyva, se ha puesto al final de la ficha el número asignado en él.

${ }^{2}$ En las fichas se transcribe el título y el inicio del sermón con la misma ortografía que aparece en la obra.

124 (an)ecdótica vol. III, núm. 2, julio-diciembre 2019 


\section{Diseño de la base de datos de sermones impresos}

Una vez terminado dicho repertorio, me surgió la inquietud de continuar con el trabajo de rescate documental de los sermones novohispanos y emprender un nuevo proyecto; así, el siguiente paso consistió en la ampliación del área de búsqueda: ya no me limitaría únicamente a las piezas resguardadas en la Biblioteca Nacional de México, sino que el objetivo sería, en esta nueva etapa de investigación, la realización de un catálogo general, el cual documentara la totalidad de sermones impresos en el territorio que se denominó la Nueva España en el siglo XVII. Para llevarlo a cabo, tomé como referencia dos repertorios bibliográficos de José Toribio Medina, tanto la monumental obra La imprenta en México como La imprenta en Puebla de los Ángeles, además de la tesis doctoral de Juan Escobedo Romero: "La imprenta en Puebla de los Ángeles 1640-1815". De ese modo, recopilé los sermones impresos durante el siglo XVII registrados en estas tres obras bibliográficas y, ya con las referencias de los textos, me di a la tarea de localizarlos en las principales bibliotecas del país que cuentan con fondos novohispanos, tales como el Fondo Reservado de la Biblioteca Nacional, la Biblioteca Nacional de Antropología e Historia "Eusebio Dávalos Hurtado", el Fondo Antiguo "José María Lafragua" de la Biblioteca de la Benemérita Universidad Autónoma de Puebla, la Biblioteca del Centro de Estudios de Historia de México CARso, la Biblioteca Cervantina del Instituto Tecnológico de Monterrey, la Biblioteca Palafoxiana, la Biblioteca "Eusebio Kino" y la Biblioteca "Francisco de Burgoa". Al terminar la búsqueda, se documentaron un total de 100 sermones de los que no se tenía registro (debido a que no formaban parte del Fondo Reservado de la Biblioteca Nacional) y se amplió y corrigió la información de las 482 fichas elaboradas en la etapa anterior de esta investigación. Así, se conformó la versión final del "Catálogo general de sermones impresos novohispanos del siglo XVII", con un total de 582 fichas reunidas.

A continuación, se presenta una ficha catalográfica de este repertorio; en ella puede verse que hubo un incremento en la cantidad de información registrada en comparación con la del primer catálogo. Se eligió, como muestra modélica, un sermón que fue incluido, posteriormente, en una colección de sermones dedicados a la beatificación de santa Teresa, publicada en Madrid en 1615:

5 VALLEJO, LUIS, O. P., Sermon, que predico el P. M. fr. Luys Vallejo, de la Orden de Predicadores, Qualificador del sancto Officio, a la Beatificacion de la Bienauenturada Madre sancta Theresa de Iesvs, en Mexico, en su casa de los Decalços Carmelitas, lunes 6. de Octubre, de 1614. dia que a la dicha Orden de Predicadores cupo, para solemnizar esta fiesta: asistiendo a ella los Señores Inquisidores. Dirigido a la Excelentissima Señora Doña Mariana Riedre, Marquesa de Guadalcasar, Virreyna desta Nueva España, $\mathcal{E}^{2}$. / / Estando Alexandro Magno en campo para romper con ciertos contrarios valerosos, que le hazian incierta la victoria, repentinamente nacieron junto a su pabellon, y tienda, dos fuentes, una de olio, otra de agua..., México, viuda de Diego López Dávalos por C. Adriano César, 1614. 


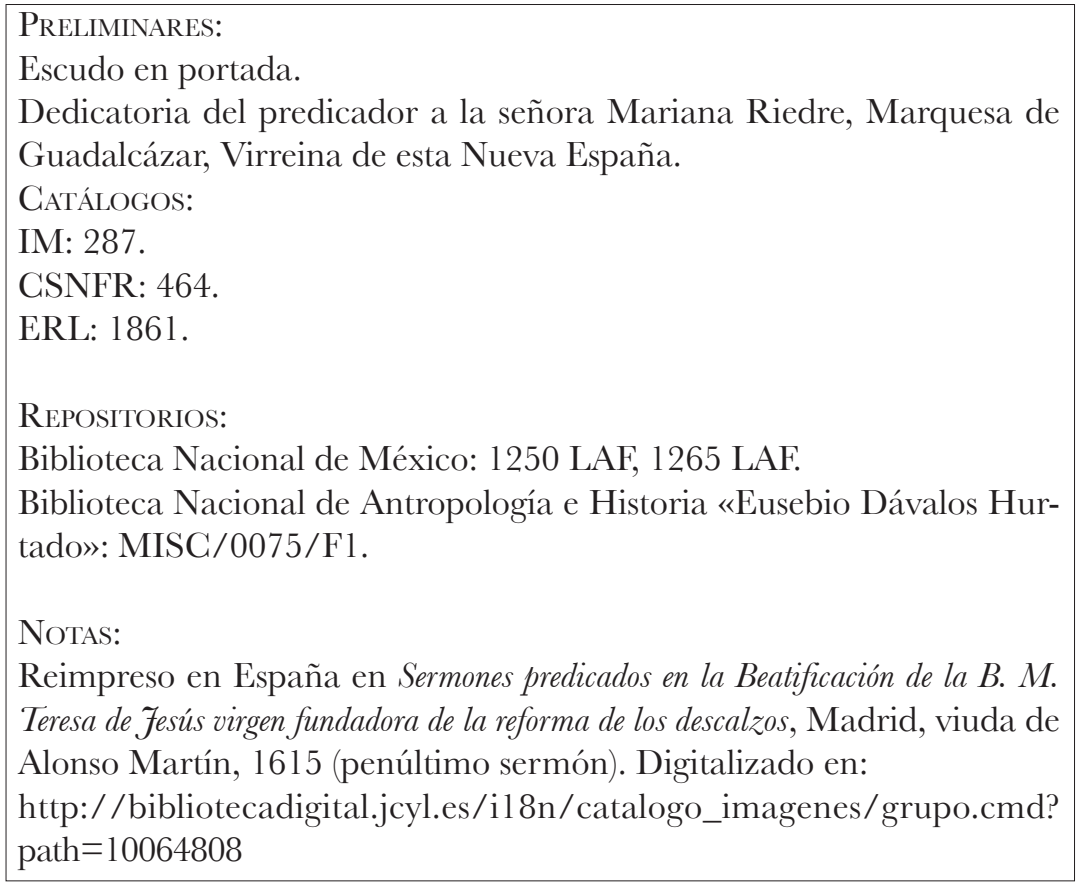

La estructura de las fichas es similar a la empleada para las del repertorio del Fondo Reservado de la Biblioteca Nacional de México, pero se incluyen algunos datos más; por ejemplo, ya no se mencionan sólo los tipos de documentos que conforman los preliminares, sino también la información de los autores y a quiénes están dirigidos. Asimismo, se ofrecen los nombres de más repertorios bibliográficos en los que se registra la obra, así como de las bibliotecas donde está depositada con su clasificación correspondiente. Por último, se presenta un apartado de notas, en el que se proporciona cualquier información de interés que se tenga sobre el documento; en el caso del ejemplo anterior, se apunta que el sermón se imprimó en España dentro de una colección de sermones, la cual se encuentra digitalizada.

Ahora bien, al ser tan grande y variada la cantidad de datos que el catálogo documenta, el manejo de la información comenzó a resultar problemático; por tal motivo, se tomó la decisión de diseñar una base de datos en el programa Access, donde se pudiera guardar la totalidad de la información relativa a la materialidad y al contenido de los sermones. Contar con una herramienta de almacenamiento y de búsqueda tan poderosa para administrar esa información permitiría presentar los elementos registrados de una manera accesible, sencilla y ordenada al usuario, quien podría realizar diversos tipos de búsqueda en ella. En otras palabras, por medio de este útil instrumento, se lograría crear la infraestructura necesaria para la investigación. Dicho sistema de acopio de información, al que estamos poco acostumbrados los estudiosos

126 (an)ecdótica vol. III, núm. 2, julio-diciembre 2019 


\section{Diseño de la base de datos de sermones impresos}

de la literatura, brinda posibilidades de trabajo más amplias y complejas que las que proporciona un repertorio impreso de manera tradicional, ya que permite realizar búsquedas específicas o mostrar determinados resultados parciales, dependiendo de las inquietudes o requerimientos de los usuarios.

Partiendo de lo anterior, en términos generales, se creó una base de datos en la que se concentrará toda la información relativa a los sermones impresos novohispanos del siglo XVII, localizados en los acervos ya mencionados. Ahí, se incluirán los autores principales, los talleres de impresión y algunos de los profesionales que laboraban en ellos, los años de publicación, las ciudades donde se imprimieron, las obras principales dentro de las que se encuentran contenidos algunos sermones, los autores secundarios (es decir, los responsables de los preliminares), los mecenas de las obras, los themas bíblicos en torno a los cuales se desarrollaban las piezas oratorias, el número de páginas - tanto de los sermones como de los preliminares—, entre otros datos.

Con esta información, será posible generar, en primera instancia, un repertorio panorámico y cronológico de dicho género en aquella centuria; además, insisto, se podrá disponer de diversos repertorios específicos, como los dedicados a los sermones novohispanos del siglo XVII, es decir: los resguardados en determinada biblioteca, los editados en la ciudad de Puebla de los Ángeles, los que fueron impresos y no han sido encontrados físicamente por ninguno de los bibliógrafos (pero de los que sí hacen mención), los de un predicador o impresor en específico, entre otros. También, se contará con una valiosa herramienta que servirá de punto de partida para futuras investigaciones sobre el tema de la oratoria sagrada en la Nueva España. Por ejemplo, será posible averiguar quiénes fueron los predicadores-literatos más destacados, con qué otros personajes importantes de la época se relacionaron, si generaron otras producciones literarias y culturales además de los sermones, qué corrientes estilísticas o ideológicas marcaron sus obras, cuáles fueron sus lecturas, qué otras personalidades pertenecieron a su círculo cercano y con quiénes tuvieron disputas, para quiénes solían escribir los sermones, quiénes los patrocinaban, ante qué auditorios predicaban, en qué festividades o tiempos litúrgicos, en qué ciudades pronunciaban e imprimían las obras, cuáles grupos literarios o intelectuales existían en la época, las relaciones que establecieron entre sí los predicadores de determinadas órdenes religiosas, quiénes eran los impresores que trabajaban en cada una de las ciudades, así como cuáles fueron los acontecimientos y las fechas más importantes desde el punto de vista de la cultura literaria de la sociedad novohispana en la que se pronunciaban oraciones sagradas, etcétera.

Ciertamente, uno de los productos más ambiciosos y útiles de este proyecto de investigación e infraestructura literarias será el rescate y la edición — de acuerdo con la metodología de la crítica textual - de una selección de los sermones más representativos, en la que se fije el texto y se proporcione información contextual de ellos. A largo 
plazo, se podrá contar un día con una Biblioteca Digital de predicadores y sermones novohispanos. Disponer de esta cantidad de documentos en línea constituirá un gran avance para los estudios sobre el tema, además de que garantizará, después del tratamiento y mantenimiento pertinente de los archivos informáticos empleados, la preservación de los textos originales custodiados tanto en nuestra Universidad como en otras bibliotecas del país que tienen un Fondo Antiguo.

También es preciso mencionar que, cuando la base de datos esté terminada, se considerará subirla a la página de Internet que el proyecto "Las literaturas en México en la época novohispana. Historia y corpus multidisciplinario" desarrolla actualmente para la difusión de los proyectos específicos que se desprenderán de éste. ${ }^{3}$

\section{Diseño de la base de datos}

Como se sabe, las bases de datos permiten almacenar una gran cantidad de información de manera ordenada y estructurada, para que ésta sea manejable y accesible. Dicha información se organiza mediante tablas, las cuales se encuentran relacionadas entre sí, que, a su vez, se conforman por campos y registros particulares.

Según se advirtió líneas arriba, la base de datos de sermones impresos novohispanos del siglo XVII se ha elaborado en el programa Access; está conformada por un total de trece tablas, y doce de ellas dependen, directa o indirectamente, de la principal, llamada SERMONEs. La imagen 1 muestra el esquema de las relaciones entre tablas, el cual se describe a continuación.

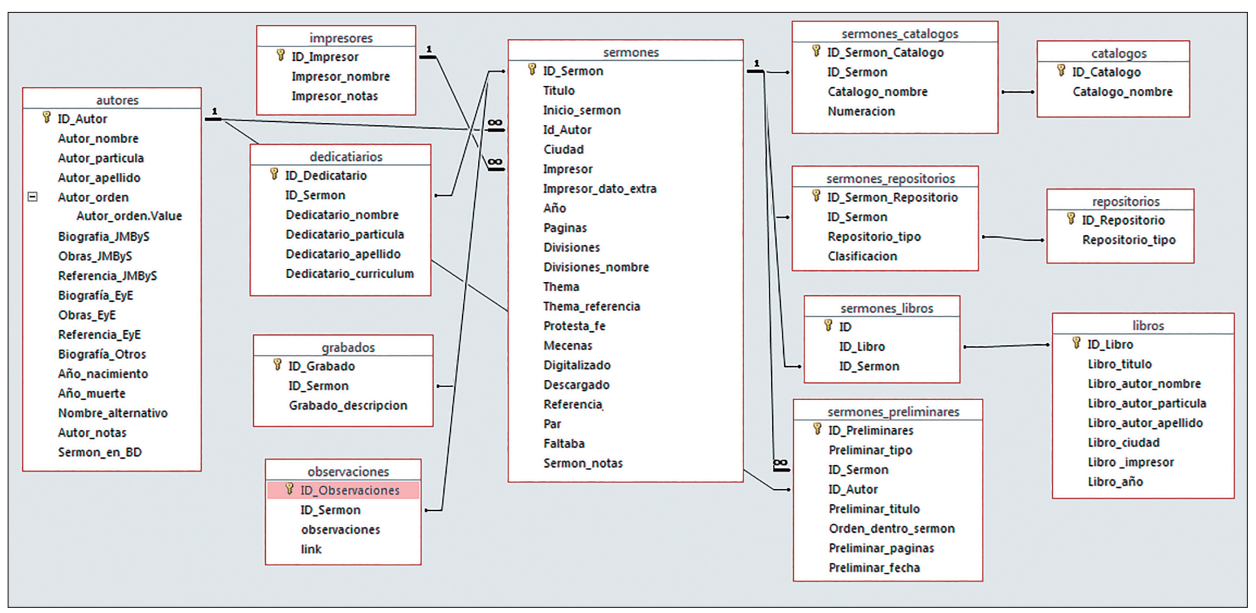

Imagen 1. Relaciones entre tablas.

\footnotetext{
${ }^{3}$ Proyecto que se lleva a cabo en el Centro de Poética del Instituto de Investigaciones Filológicas.
} 


\section{Diseño de la base de datos de sermones impresos}

La tabla SERMONES cuenta con 21 campos:

\begin{tabular}{|c|c|}
\hline Nombre del campo & DesGripaión \\
\hline ID_Sermon* & $\begin{array}{l}\text { Es el número irrepetible que identifica unívocamente cada } \\
\text { uno de los registros que conforman la tabla. }\end{array}$ \\
\hline Titulo & $\begin{array}{l}\text { Registra, como su nombre lo indica, el título del sermón tal } \\
\text { como aparece en la portada de la obra. Se transcribe respe- } \\
\text { tando la ortografía original. }\end{array}$ \\
\hline Inicio_sermon & $\begin{array}{l}\text { Contiene las líneas iniciales del sermón, e igual que en el } \\
\text { campo anterior, se respeta la ortografía original del texto.** }\end{array}$ \\
\hline ID_Autor & $\begin{array}{l}\text { Es el número irrepetible que identifica a cada uno de los } \\
\text { autores de los sermones. }\end{array}$ \\
\hline Ciudad & $\begin{array}{l}\text { Brinda la opción de elegir, gracias a un menú desplegable, } \\
\text { tres opciones: las dos ciudades de impresión en esa época, } \\
\text { México o Puebla; y, si se desconoce el lugar de impresión, se } \\
\text { cuenta con la abreviatura s. l. (véase imagen 2). }\end{array}$ \\
\hline Impresor & $\begin{array}{l}\text { Igual que en el campo anterior, se tiene la opción de elegir el } \\
\text { nombre del impresor de la obra en un listado. Si el impresor } \\
\text { no es conocido, se podrá escoger: s. p. i. }\end{array}$ \\
\hline Impresor_dato_extra & $\begin{array}{l}\text { Sólo se emplea en caso de que se tenga alguna información } \\
\text { adicional del impresor en el mismo pie de imprenta, por } \\
\text { ejemplo: el lugar de su establecimiento o los colaboradores } \\
\text { que hicieron posible la edición. }\end{array}$ \\
\hline Año & Almacena el año en el que fue publicado el sermón. \\
\hline Paginas & $\begin{array}{l}\text { Contiene la información del número de páginas del sermón } \\
\text { sin contar los preliminares, ya que el número de páginas de } \\
\text { cada uno de éstos se contabiliza en la tabla SERMONES_PRE- } \\
\text { LIMINARES. }\end{array}$ \\
\hline Divisiones & $\begin{array}{l}\text { Permite la opción de marcar una casilla dentro del campo } \\
\text { en caso de que el sermón cuente con divisiones claras en el } \\
\text { cuerpo del texto (véase imagen } 3 \text { ). }\end{array}$ \\
\hline Divisiones_nombre & $\begin{array}{l}\text { Si la casilla del campo anterior fue marcada, entonces en } \\
\text { éste se registra tanto el número de partes en las que se divide } \\
\text { el sermón como el nombre (en caso de tener uno) que se le } \\
\text { da a dichas partes, por ejemplo: puntos, párrafos, discursos, } \\
\text { meditaciones, etcétera. }\end{array}$ \\
\hline
\end{tabular}

* Tanto en los nombres de los campos como en los de las tablas se han omitido los acentos por cuestiones técnicas de compatibilidad informática.

** Esta información resulta útil cuando se encuentra una obra sin portada, debido a que, al comparar el inicio de los textos, se puede identificar la obra. 


\begin{tabular}{|c|c|}
\hline Thema & $\begin{array}{l}\text { Contiene la transcripción del thema, es decir, la cita bíblica en } \\
\text { latín en torno a la cual gira el desarrollo del sermón. En oca- } \\
\text { siones se podrá tener más de un thema por documento. }\end{array}$ \\
\hline Thema_referencia & $\begin{array}{l}\text { Documenta la referencia bíblica (libro, capítulo, versículo) } \\
\text { de donde fue extraído el thema. }\end{array}$ \\
\hline Protesta_fe & $\begin{array}{l}\text { Documenta determinadas iniciales que algunos sermones } \\
\text { registran al final de la última página, las cuales tienen por } \\
\text { objeto afirmar que el sermón se apega a los dogmas de la } \\
\text { Iglesia católica. Estas iniciales pueden presentar ligeras va- } \\
\text { riaciones de un sermón a otro, por lo que resulta importante } \\
\text { documentarlas.*** }\end{array}$ \\
\hline Mecenas & Registra el nombre del personaje que patrocinó el sermón. \\
\hline Digitalizado & $\begin{array}{l}\text { Permite señalar si el sermón ha sido ya digitalizado, con la } \\
\text { finalidad de integrar la reproducción de éste a la base de } \\
\text { datos.**** }\end{array}$ \\
\hline Descargado & $\begin{array}{l}\text { Proporciona la opción de marcar si el sermón ha sido des- } \\
\text { cargado e integrado a la base de dados, en caso de que el } \\
\text { repositorio que lo resguarda ya lo tenga digitalizado. }\end{array}$ \\
\hline Referencia & $\begin{array}{l}\text { Este campo brinda el nombre de la carpeta en la que se en- } \\
\text { cuentran almacenadas las imágenes del sermón en cuestión. }\end{array}$ \\
\hline Faltaba & $\begin{array}{l}\text { Documenta los sermones que no están registrados en el } \\
\text { "Catálogo de sermones impresos novohispanos del siglo XVII } \\
\text { del Fondo Reservado de la Biblioteca Nacional". }\end{array}$ \\
\hline Par & $\begin{array}{l}\text { Este campo también tiene la opción de marcar una casilla } \\
\text { en caso de que el sermón haya sido publicado en par. Se } \\
\text { consideró importante señalar esta forma de publicación con } \\
\text { la intención de contar con un registro, ya que se han encon- } \\
\text { trado varios sermones publicados de dicha manera. }\end{array}$ \\
\hline Sermon_notas & $\begin{array}{l}\text { Finalmente, este campo puede contener cualquier tipo de } \\
\text { observación que sea de interés con respecto al sermón que } \\
\text { se registra. }\end{array}$ \\
\hline
\end{tabular}

*** Idalia García propone que el significado de las iniciales O.S.C.S.M.E.C.A.R sería: Omnia Sub Correctione Sancta Matris Ecclesiae Catholicae Apostolicae Romanae. Frase que se puede traducir como "Todo bajo la corrección de la Santa Madre Iglesia Católica, Apostólica y Romana” (231-236).

**** La diferencia entre este campo y el siguiente es que en "Digitalizado" se señalan las obras que se han reproducido con la finalidad de añadirlas a la base datos; mientras que en "Descargado" la reproducción la realizó el repositorio donde se encuentra depositada la obra. 


\section{Diseño de la base de datos de sermones impresos}

El número de registros (o filas) que conformarán la tabla anterior será de 582, pues corresponden con el número de fichas que recoge el "Catálogo general"; sin embargo, no se descarta el hallazgo de más sermones durante el tiempo de elaboración de la base de datos, lo cual incrementaría el número de registros.

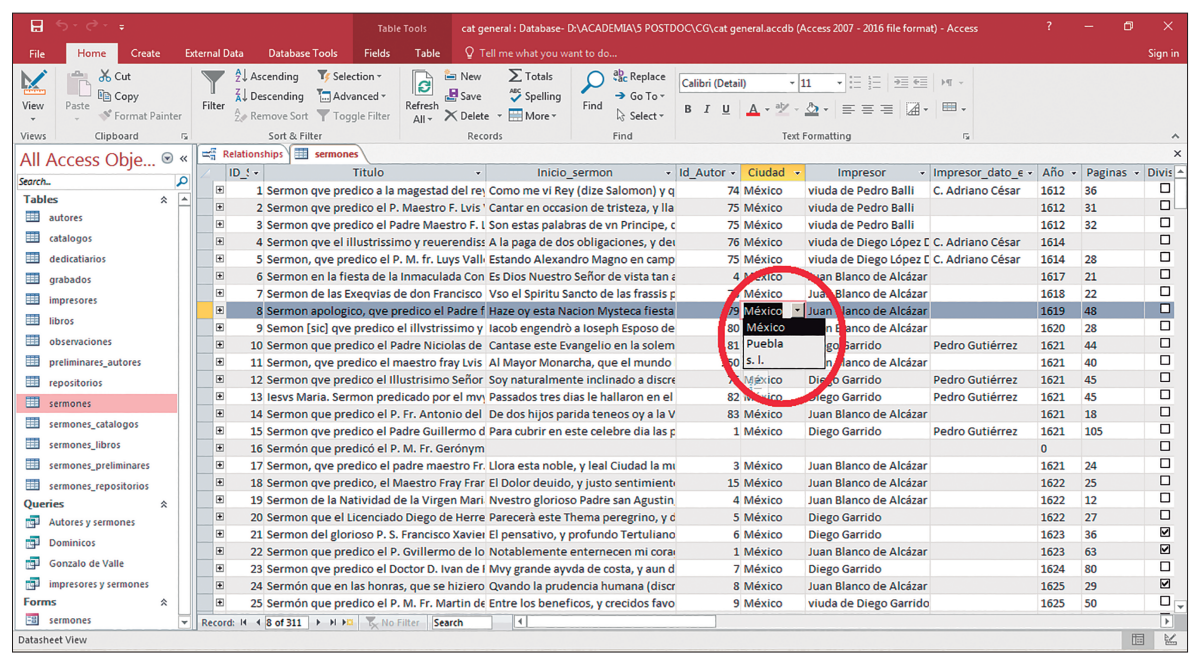

Imagen 2. Menú desplegable del campo Ciudad.

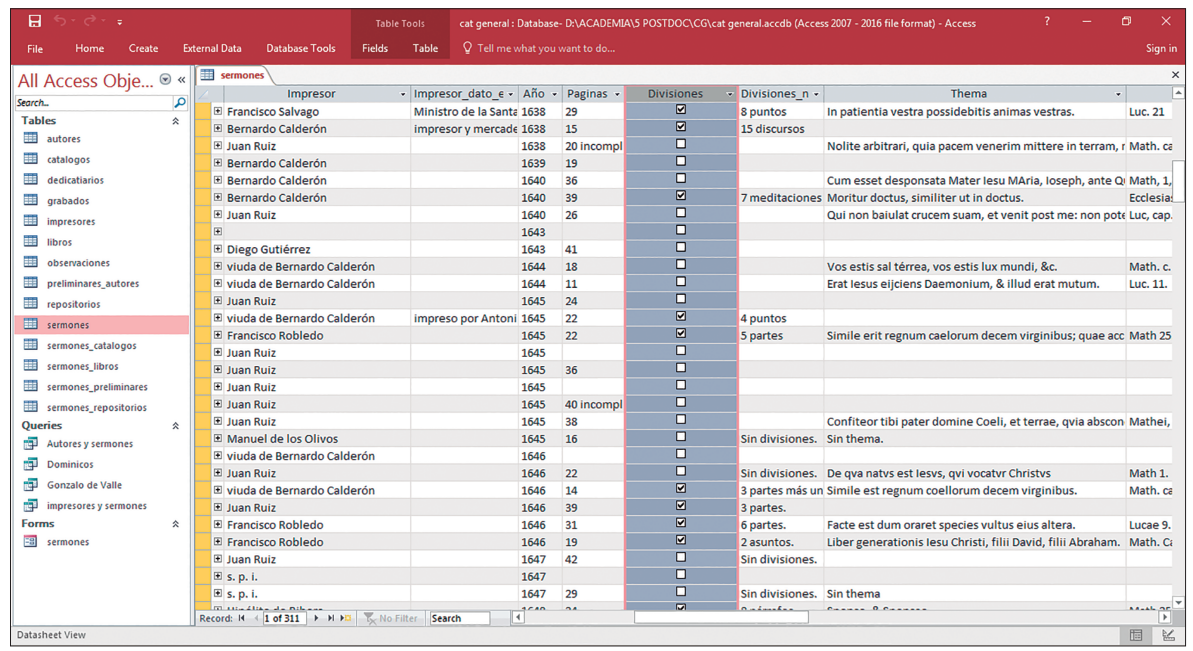

Imagen 3. Opción de marcado Sí/No en la casilla del campo Divisiones.

Ahora bien, cabría insistir en que, aun cuando para el gestor de la base de datos no existe una tabla más importante que otra, desde el punto de vista de su diseño conceptual, la principal corresponde a la de SERMONEs, pues, como se dijo, de ella dependen las demás tablas, ya sea directa o indirectamente; asimismo, es la que contiene 


\section{Cecilia A. Cortés Ortiz}

una mayor cantidad de información y datos fundamentales referentes a los sermones. Como se observa en la imagen 1, nueve tablas se relacionan de manera directa con la tabla SERMONES, de las cuales sólo cuatro están vinculadas única y exclusivamente con ella: IMPRESORES, DEDICATARIOS, OBSERVACIONES Y GRABADOS.

La tabla IMPRESORES contiene los nombres de todos los impresores que editaron piezas de oratoria sagrada durante el siglo XVII en la Nueva España; cuenta con tres campos: ID_Impresor (el número irrepetible que identifica unívocamente cada uno de los registros guardados), Impresor_nombre (nombre y apellidos, en este orden, de cada uno de los impresores que sacaron a la luz sermones en dicha centuria) e Impresor_ notas (cualquier información importante y concisa referente al impresor en cuestión).

La tabla DEDICATARIos consigna el nombre de los personajes a los que se les dedicó alguno de los sermones; está conformada por seis campos: ID_Dedicatario (el número irrepetible que identifica a cada uno de los personajes registrados), ID_Sermon (se toma de la tabla SERMONES), Dedicatario_nombre (nombre de pila del "dedicatario"), Dedicatario_particula (partícula del apellido, en caso de tenerla, por ejemplo: "del" si el personaje se apellida "del Valle", "de" si se apellida "de Toledo", "de la" si su apellido es "de la Cerda", etcétera), Dedicatario_apellido (apellidos del personaje en cuestión), ${ }^{4}$ Dedicatario_curriculum (información referente al "dedicatario" proporcionada en la portada o en los preliminares de la obra, como pueden ser títulos nobiliarios o cargos eclesiásticos).

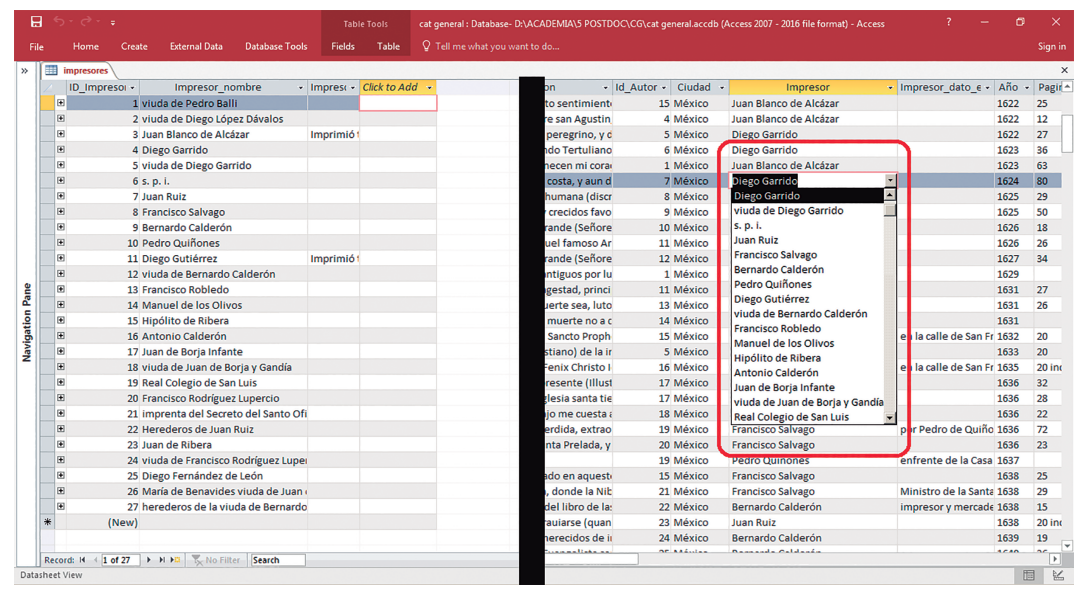

Imagen 4. Opciones en el campo Impresor de la tabla SERMONES. ${ }^{5}$

\footnotetext{
${ }^{4}$ La razón de dividir el nombre del personaje de esta manera se explicará en la parte dedicada a la tabla AUTORES.

${ }^{5}$ En esta imagen, se muestra la tabla IMPRESORES del lado izquierdo, mientras que del derecho, la tabla sermones con el menú desplegable en el campo Impresor.
} 
La tabla GRABADOS documenta la información relativa a los grabados encontrados en los sermones; cuenta con tres campos: ID_Grabado (número irrepetible que identifica cada uno de los registros de los grabados que se guardan en la tabla), ID_ Sermon (número de la tabla SERMONes) y Grabado_descripcion (breve descripción de los grabados encontrados en el texto).

Para la información extra que se encuentre de algún sermón, se incluye la tabla OBSERVACIONES, la cual contiene cuatro campos: ID_Observaciones (número único identificador de cada uno de los registros), ID_Sermon (número identificador de los registros de la tabla SERMONES), Observaciones (información adicional del sermón en cuestión) y Link (enlace a Internet del sermón, en caso de que éste se encuentre digitalizado en la red). Las tres tablas anteriores pueden considerarse una extensión de la principal (SERMONES).

Siguiendo con la descripción de la base de datos, se observa una conexión triangular, puesto que dos tablas se relacionan de manera directa entre ellas y también con la principal: AUTORES y SERMONES_PRELIMINARES. La imagen 5 presenta exclusivamente la correspondencia de estas tres tablas vinculadas por el campo ID_Autor, mientras que las tablas SERMONES y SERMONES_PRELIMINARES se relacionan, además, por medio del ID_Sermon:

La tabla AUTORES es la segunda más importante de la base de datos, pues almacena información primordial sobre los autores de los textos, tanto de los sermones como de los preliminares; se encuentra conformada por 17 campos: ID_Autor (número único que la base de datos asigna automáticamente para identificar cada uno de los registros), Autor_nombre (nombre de pila del autor), Autor_particula (partícula del apellido del autor en caso de tenerla) y Autor_apellido (apellidos del autor). Se optó por colocar el nombre completo del autor dividido en tres campos porque será de mayor utilidad cuando se desee extraer información de la base de datos; por ejemplo, en caso de querer elaborar un catálogo que presente a los autores por apellido, sólo será posible hacerlo si el nombre del autor está dividido en las tres partes mencionadas. Los siguientes campos son: Autor_orden (con un menú desplegable que muestra las órdenes religiosas o los cargos eclesiásticos del autor, véase la imagen 6), Biografia_JMByS (datos biográficos del autor que José Mariano Beristáin y Martín de Souza proporciona en su Biblioteca hispanoamericana septentrional), ${ }^{6}$ Obras_JMByS (las obras del autor en cuestión que el ya citado bibliógrafo recoge en su Biblioteca), Referencia_JMByS (la parte de la Biblioteca hispanoamericana septentrional en la que encontramos la información), Biografia_EyE, Obras_EyE, Referencia_EyE (proporcionan esa información específica del autor que Juan José de Eguiara y Egu-

\footnotetext{
${ }^{6}$ Desafortunadamente, no se cuenta con la biografia de todos los autores registrados en la base de datos.
} 
ren consignó en su Bibliotheca Mexicana), ${ }^{7}$ Biografia_otros (los datos biográficos del autor encontrados en otra fuente), Año_nacimiento (año en el que nació el autor), Año_muerte (año de su fallecimiento), Nombre_alternativo (las variaciones del nombre del autor — con un apellido más o con uno menos-, este campo permitirá al usuario hacer búsquedas más amplias, pues no será necesario escribir el nombre del autor de una manera exacta), Autor_notas (cualquier información adicional y precisa sobre el autor), Sermon_en_BD (permite señalar si se registró un sermón del autor en la base de datos, marcando esta casilla se puede saber si el personaje es autor de sermones, de preliminares o de ambos).

La tabla SERMONES_PRELIMINARES es la tercera en orden de importancia por la cantidad de información que incluye; se compone de ocho campos: ID_Preliminares (número asignado automáticamente para identificar cada uno de los registros), Preliminar_tipo (permite elegir, mediante un menú desplegable, entre los diversos tipos de documentos que pueden formar parte de los preliminares), ID_Sermon (número asignado para identificar cada uno de los sermones), ID_Autor (el número irrepetible que identifica a cada uno de los autores almacenados en la tabla AUTORES), Preliminar_titulo (título completo del preliminar tal como se encuentra en el texto, pero con la ortografía actual), Orden_dentro_sermon (menú desplegable que permite elegir el orden de aparición que presenta el preliminar dentro de la obra), ${ }^{8}$ Preliminar_paginas (número de páginas del texto, para poder establecer con cuántas páginas cuenta la obra completa, incluidas las de cada una de las partes que la conforman), Preliminar_fecha (fecha en la que se escribió el preliminar).

Las siguientes seis tablas presentan una estructura similar para que puedan relacionarse con la tabla SERMONEs (véase imagen 1). En ellas se almacenan tres tipos de datos referentes a: los catálogos que han documentado alguno de los sermones registrados en esta base de datos; las bibliotecas donde se encuentran resguardadas las piezas de oratoria sagrada, y la información de la obra principal en la que se editaron algunos sermones (en el caso de que hayan sido impresos dentro de un sermonario o de una obra de otro tipo que no sea el sermón suelto). Para organizar estos tres rubros, se requirieron dos tablas por cada uno de ellos: en una tabla principal se almacenaron los datos sobre los catálogos empleados, las bibliotecas en las que se han localizado sermones y los libros en los que se han encontrado piezas de oratoria sagrada. Una segunda tabla funge como un puente, puesto que es necesaria para unir la información

${ }^{7}$ Ambas obras son fundamentales en lo referente a la bio-bibliografia de la época colonial, por ello se toman como base para extraer información de los personajes documentados en esta base de datos.

${ }^{8}$ Esta información resulta útil en caso de querer ordenar todos los documentos preliminares que le corresponden a un sermón, siguiendo el orden que presentan en el impreso. 


\section{Diseño de la base de datos de sermones impresos}

sobre catálogos, bibliotecas o libros con cada uno de los sermones registrados en la tabla SERMONES, es decir, esta tabla muestra con exactitud a qué sermón le corresponde la información consignada en la primera tabla.

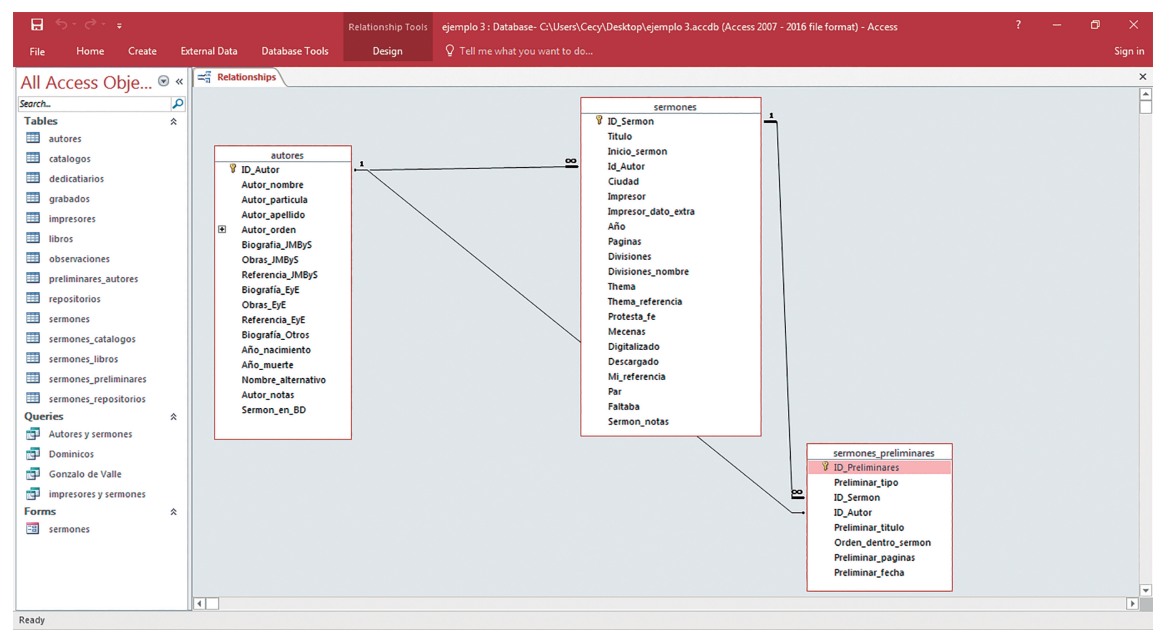

Imagen 5. Relación triangular entre las tablas SERMONES, AUTORES y SERMONES_PRELIMINARES. ${ }^{9}$

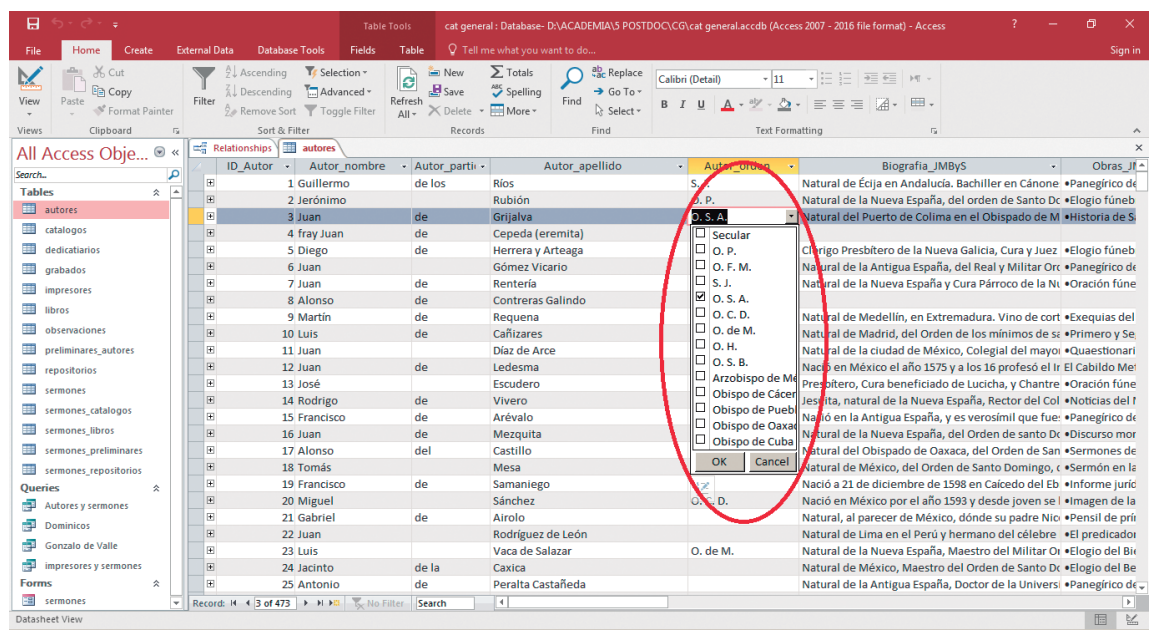

Imagen 6. Menú desplegable para marcar más de una opción del campo Autor_orden de la tabla AUTORES.

Una vez aclarado lo anterior, continúo con la descripción de las seis tablas aludidas. La denominada catalogos cuenta con dos campos: ID_Catalogo (número

${ }^{9}$ Presento únicamente estas tres tablas para mostrar de forma clara la relación existente entre ellas. 
identificador de cada uno de los registros de la tabla) y Catalogo_nombre (contiene los seis catálogos en los que se han documentado los textos). Como ya se ha dicho, esta tabla se relaciona con la de SERMONES_CATALOGOS (y a su vez con la de SERMONES), compuesta por cuatro campos: ID_Sermon_Catalogo (número asignado por la base de datos para identificar los registros consignados), ID_Sermon (empleado para definir con exactitud el sermón documentado en los catálogos), Catalogo_nombre (despliega un menú para elegir entre las seis opciones de catálogos ya registrados en la tabla CATALOGOS), Numeracion (número asignado a un determinado sermón en un catálogo específico).

La tabla RePositorios presenta, al igual que la de catalogos, dos campos: ID_ Repositorios (número que identifica cada uno de los repositorios registrados) y Repositorio_tipo (nombres de las distintas bibliotecas, tanto nacionales como del extranjero, en las que se han localizado sermones), este campo es compartido con la tabla SERMONES_REPOSITORIOS, lo cual establece una relación entre ambas; dicha tabla se encuentra conformada por cuatro campos: ID_Sermon_Repositorio (número para la identificación de los registros), ID_Sermon (permite relacionar los datos de esta tabla con las obras registradas en la de SERMONES), Repositorio_tipo (menú desplegable para elegir la biblioteca donde se resguarda el sermón del que se está almacenando información), Clasificacion (signatura que una biblioteca específica da al sermón).

La información referente a los libros o sermonarios en los que pueden aparecer sermones se documenta en la tabla LIBRos, la cual cuenta con ocho campos: ID_ Libro (número que identifica cada uno de los registros), Libro_titulo (título de la obra), Libro_autor_nombre (nombre de pila del autor de la obra), Libro_autor_ particula (si el apellido tiene una partícula, quedará registrada en este campo), Libro_autor_apellido (apellido del autor), Libro_ciudad (ciudad de impresión del libro), Libro_impresor (impresor de la obra) y Libro_año (año de publicación de la obra). Como en los dos casos anteriores, esta tabla contiene información útil para la de SERMONES_LIBROS, con la que se relaciona directamente y la cual consta de tres campos: ID_Sermones_Libros (identifica los registros de esta tabla), ID_ Libro (vincula la tabla con la de LIBRos) e ID_Sermon (relaciona el sermón con el libro en el que se encuentra contenido).

\section{Conclusión}

En estos momentos, la base de datos es una investigación que se encuentra en desarrollo. Se han guardado los datos de 311 sermones de los 582 que conformarán la base de datos. 


\section{Diseño de la base de datos de sermones impresos}

Cabe subrayar dos aspectos importantes referentes al diseño de esta base: la forma en la que se almacenan los datos es totalmente independiente de la presentación de los mismos, la cual dependerá de las peticiones que el usuario realice en la base de datos; por ejemplo, se puede extraer sólo la información de los predicadores de una orden eclesiástica específica. El segundo aspecto es que el diseño obedece fundamentalmente a la funcionalidad del almacenamiento de la información: los datos deben ordenarse de la mejor manera posible para evitar ambigüedades y repeticiones, puesto que, al contar con un buen diseño, la información podrá presentarse de forma más rápida y sencilla.

En pleno siglo xxI, resulta obligado acudir a las nuevas tecnologías en beneficio de cualquier proyecto de investigación que se esté llevando a cabo. Las Humanidades, en general, y la Filología, en particular, no se han quedado atrás, muestra de ello es el auge de las Humanidades Digitales. El proyecto que he presentado puede inscribirse en esta área de investigación, pues pretende aprovechar las herramientas informáticas actuales, con la finalidad de favorecer los estudios filológicos al realizar un mejor acopio de la información y un manejo óptimo de la misma. Trasladar este trabajo de bibliografia material de los sermones impresos novohispanos del siglo XVII a un soporte informático ha representado dar un paso más en la labor de rescate documental de los textos, pues la información recopilada no se quedará únicamente en los catálogos impresos, sino que se incluirá en la base de datos con el propósito de que, al clasificarla mejor, sea más accesible. Así, el empleo de la tecnología permitirá que los datos almacenados tengan un rango de alcance mayor que el que podría tener el catálogo impreso.

Si se hace un balance en el área de Literatura, se podrá constatar que, por lo general, no se suelen utilizar los avances de la tecnología; sin embargo, en estos tiempos que corren, siempre que sea pertinente para la materia de estudio, los proyectos deberían valerse, lo más posible, de las herramientas tecnológicas, con el fin de mejorar los resultados de la investigación y abrir nuevas rutas interpretativas a partir del trabajo de fuentes originales.

\section{Bibliografía}

Beristáin De SouzA, José Mariano

Biblioteca hispanoamericana septentrional. 2a edición (facsimilar). 3 volúmenes. México: Universidad Nacional Autónoma de México/Instituto de Estudios y Documentos Históricos/ Claustro de Sor Juana, 1980-1981.

Cortés Ortiz, Cecilia A.

"Catálogo de sermones impresos novohispanos del siglo XVII del Fondo Reservado de la Biblioteca Nacional de México", en "Sermones impresos novohispanos del siglo XVII: la 
edición del sermonario Historias varias canónicas moralizadas en sermones de Antonio Delgado y Buenrostro". Tesis de doctorado. Salamanca: Universidad de Salamanca, 2015.

Eguiara y Eguren, Juan José de

Bibliotheca Mexicana. Prólogo y versión española de Benjamín Fernández Valenzuela. Estudio preliminar, notas, apéndices, índices y coordinación general de Ernesto de la Torre Villar. México: Universidad Nacional Autónoma de México, Coordinación de Humanidades, 1986.

Escobedo Romero, Juan

"La imprenta en Puebla de los Ángeles 1640-1815". Tesis de doctorado. Alcalá de Henares: Universidad de Alcalá, 2011.

GARcía, Idalia

"Religión y tipografia: la protesta de fe en el impreso novohispano", en Felipe Martínez Arellano y Juan José Calva González (compiladores). Memoria del XXVI Coloquio de Investigación Bibliotecológica y de la Información. México: Universidad Nacional Autónoma de México, Centro Universitario de Investigaciones Bibliotecológicas, 2009, 215-236.

Herrejón Peredo, Carlos

Del sermón al discurso cívico: México 1760-1834. Zamora (Michoacán): El Colegio de Michoacán/El Colegio de México, 2003.

Medina, José Toribio

La imprenta en México (1539-1821). Edición facsimilar de 1909. 8 volúmenes. México: Universidad Nacional Autónoma de México, Instituto de Investigaciones Bibliográficas, 1989.

La imprenta en la Puebla de los Ángeles (1640-1821). México: Universidad Nacional Autónoma de México, Instituto de Investigaciones Bibliográficas, 1990.

Ramírez Leyva, Edelmira

Cartas pastorales, elogios fúnebres, oraciones, panegínicos, sermones y otros géneros de oratoria sagrada de la colección Lafragua del Fondo Reservado de la Biblioteca Nacional de México. México: Universidad Nacional Autónoma de México, Instituto de Investigaciones Bibliográficas/Universidad Autónoma Metropolitana, Departamento de Humanidades, 1992.

WaLde Moheno, Lillian von der

"Artes praedicandi. La estructura del sermón”, en Destiempos, año 3, número 18 (enero-febrero, 2009) 1-14.

138 (an)ecdótica vol. III, núm. 2, julio-diciembre 2019 